Check for updates

Cite this: RSC Adv., 2018, 8, 230

Received 3rd November 2017 Accepted 6th December 2017

DOI: $10.1039 / c 7 r a 12092 c$

rsc.li/rsc-advances

\section{Combination of icariin and oleanolic acid attenuates in vivo and in vitro glucocorticoid resistance through protecting dexamethasone- induced glucocorticoid receptor impairment}

\author{
Xiu-Feng Tang, ${ }^{a}$ Xiao-Xi Li, ${ }^{a}$ Yu-Heng Chen, ${ }^{a}$ Ying-Ying Gao, ${ }^{a}$ Ping Yu, ${ }^{a}$ Li-Ping $\mathrm{Xu}^{\star a}$ \\ and Ren-Hui Liu (D)*ab
}

Glucocorticoid resistance (GCR) remains a significant problem and is the most important reason for treatment failure of glucocorticoids (GCs). How to increase the sensitivity to GCs and exploring new agents to overcome GCR is of great significance. Herein, we report for the first time that the effects of combination of icariin and oleanolic acid (OA) on dexamethasone (Dex)-induced glucocorticoid receptor (GR) impairment in vivo and in vitro. Compared with the use of Dex or combination of icariin and OA alone, co-administration resulted in a significant increase in apoptosis, GR protein, GR binding and GR $\alpha$ protein both in GC-sensitive CEM-C7 and GC-resistant CEM-C1 cells and a decrease in GR $\beta$ protein and $\mathrm{GR} \beta / \mathrm{GR} \alpha$ only in CEM-C1 cells. Furthermore, an ovalbumin-induced rat asthma model was chosen to evaluate the effects of co-administration of Dex and combination of icariin and OA in vivo. Compared with the use of Dex alone, co-administration could protect blood lymphocyte from excessive apoptosis, significantly increasing GR binding, GR protein and mRNA of GR $\alpha$ while decreasing GR $\beta$ protein and mRNA of GR $\beta$. The results suggested that combination of icariin and OA could increase sensitivity to GCs through attenuating in vivo and in vitro Dex-induced GR impairment.

\section{Introduction}

Glucocorticoids (GCs) are among the most prescribed drugs in the world and are widely used in chemotherapy either as a primary cytotoxic drug targeting cancer cells (as in acute leukemia, lymphoma and multiple myeloma) or to reduce inflammation, prevent allergic reactions, etc. ${ }^{\mathbf{1 , 2}}$ However, when GCs are administered in high doses or used long-term, a series of side effects would be produced, such as growth stunting in children, hypothalamic-pituitary-adrenal (HPA) axis dysfunction, osteopenia, GC dependence and GC resistance (GCR). ${ }^{3-5}$ GCR remains a significant problem and is the most important reason for treatment failure of GCs. Although most studies have focused on asthma, GCR is found in many other autoimmune and inflammatory diseases. For instance, $30 \%$ of rheumatoid arthritis patients and almost all chronic obstructive pulmonary disease patients exhibit GCR. ${ }^{6}$ Therefore, how to increase the

${ }^{a}$ School of Traditional Chinese Medicine, Capital Medical University, Room 283, Building Jie-Ping, No. 10 Xitoutiao, Youanmenwai, Fengtai District, Beijing 100069, China. E-mail: tangxf927@126.com; lixiaoxi0314@163.com; angela2155110@163. com; yingying1039@163.com; 373718234@qq.com; xulp@ccmu.edu.cn; gzblrh45@ ccmu.edu.cn; Fax: +86-10-83911627; Tel: +86-10-83911630; +86-10-83911639

${ }^{b}$ Beijing Key Lab of TCM Collateral Disease Theory Research, Capital Medical University, Room 284, Building Jie-Ping, No. 10 Xitoutiao, Youanmenwai, Fengtai District, Beijing 100069, China sensitivity to GCs and exploring new agents to overcome GCR is of great significance.

GC signaling has various effects on the immune system, and extensive research has been carried out on T lymphocytes. ${ }^{7}$ Loss of $\mathrm{T}$ cells via apoptosis is a major cause of the immunosuppressive actions of GCs. ${ }^{8}$ GCR is often associated with the development of resistant $\mathrm{T}$ cells that no longer respond to GCevoked apoptosis. ${ }^{9}$ The primary action of GCs is mediated through their interactions with the glucocorticoid receptor (GR). ${ }^{1}$ GR protein down-regulation could be the result of many different mechanisms of GCR, ${ }^{10}$ including homologous downregulation (ligand-induced down-regulation of GR), reduced transcription, ${ }^{\mathbf{1 1}}$ decreased stability of GR mRNA $^{\mathbf{1 2}}$ and GR protein degradation. ${ }^{13}$ GR transcriptional activity correlates with susceptibility of cells to GC-evoked apoptosis. ${ }^{\mathbf{1 4}}$ Alternative splicing of GR near the 30 UTR in exon 9 generates two major isoforms (GR $\alpha$ and GR $\beta$ ). The classical human GR $\alpha$ consists of 777 amino acids, while GR $\beta$ consists of only 742 amino acids and is unable to bind GCs, resulting in a dominant negative protein. Subsequently, up-regulation of the dominant negative GR $\beta$ isoform has been found to be associated with GR insensitivity in many diseases. ${ }^{\mathbf{1 5}}$ In addition, problems with chaperone proteins and cofactors involved in GR signaling can contribute to reduced GC sensitivity. In short, GC insensitivity could be primarily caused by problems in the GR protein itself. 
According to traditional Chinese medicine (TCM) theories, the use of GCs in clinical practice affects kidney function and leads to kidney deficiency syndrome. ${ }^{16}$ The decrease in GR protein or GR binding caused by administration of GCs has been proved to play a key role in the pathogenesis of kidney deficiency syndrome. Hence, many TCM doctors adopt the method of tonifying the kidney to prevent GR impairment. Epimedii Folium (EF) and Ligustri Lucidi Fructus (LLF) have been documented as kidney-yang and kidney-yin replenishing herbs, respectively. In our previous research, we have demonstrated that the decoction of EF and LLF could prevent the decrease of mRNA and protein expression of GR induced by dexamethasone (Dex) in asthmatic rats, ${ }^{17}$ and the active ingredients of EF and LLF (total flavonoids and triterpenoids) can effectively enhance the sensitivity of asthmatic rats to budesonide (Bun) via increasing lymphocyte apoptosis and balancing GR/heat shock protein 90 (HSP90). ${ }^{18}$ The active ingredients of EF and LLF primarily contain icariin and oleanolic acid (OA). Icariin is a major constituent of $\mathrm{EF}$ and exerts a wide range of pharmacological activities. It has been reported that icariin can alter the expression of GR, regulate the normalization of GR distribution between the cytoplasm and the nucleus and protect against corticosterone-induced apoptosis. ${ }^{19,20} \mathrm{OA}$ is one of the best known bioactive pentacyclic triterpenoids and of great interest to scientists because of its several biological activities, including anti-HIV, diuretic, nephroprotective, antidiabetic, antioxidant and hepatoprotective activities. Recent research has demonstrated that OA prevents Dex-induced hypertension in rats through its antioxidant and nitric oxide releasing action. ${ }^{21,22}$ We speculate that the combination of icariin and OA has the function of increasing protein and mRNA expression of GR. In the present study, a combination of icariin and OA was administered to investigate its potential for sensitizing GCresistant CEM-C1 cells to Dex, and the results showed that the combination could effectively sensitize GC-resistant CEM-C1 cells to Dex-induced apoptosis by activation of GR and regulate GR isoforms. Moreover, we selected ovalbumin (OVA)induced asthma rats to explore the preventive effects of the combination of icariin and OA on Dex-induced GR impairment in vivo.

\section{Materials and methods}

\subsection{Cell lines and treatment protocol}

Human T-ALL cell lines of GC-sensitive CEM-C7-14 and GCresistant CEM-C1-15 were purchased from Shanghai Huzhen Biological Technology Co., Ltd (Shanghai, China). We refer to these cell lines as CEM-C7 and CEM-C1 in the following text. Both CEM-C7 and CEM-C1 cells were maintained in RPMI-1640 medium supplemented with $10 \%$ fetal bovine serum, $2 \mathrm{mM}$ glutamine and $100 \mathrm{U} \mathrm{mL}^{-1}$ penicillin/streptomycin and cultured at $37{ }^{\circ} \mathrm{C}$ in $5 \% \mathrm{CO}_{2}$ humidified atmosphere. ${ }^{23}$ Cells were passaged once every 3 days. Cells in the logarithmic growth phase were seeded in a 6-well plate at a density of $4 \times 10^{5} \mathrm{~mL}^{-1}$ and then treated with $30 \mu \mathrm{L}$ Dex $\left(10^{-6} \mathrm{~mol} \mathrm{~L}^{-1}\right)$, icariin $(100 \mathrm{mg}$ $\mathrm{mL}^{-1}$ ), OA (100 $\mathrm{mg} \mathrm{mL}^{-1}$ ), icariin\&OA (icariin $50 \mathrm{mg} \mathrm{mL}^{-1}$ and OA $50 \mathrm{mg} \mathrm{mL}^{-1}$ ), and Dex + icariin\&OA (Dex $10^{-6} \mathrm{~mol} \mathrm{~L}^{-1}$, icariin $50 \mathrm{mg} \mathrm{mL}^{-1}$ and OA $50 \mathrm{mg} \mathrm{mL}^{-1}$ ) for $24 \mathrm{~h}$. Dex was obtained from Sigma-Aldrich, USA. Icariin [98\% purity, as verified by high-performance liquid chromatography (HPLC)] and OA (99.44\% purity, as verified by HPLC) used in this study were purchased from Chengdu Biopurify Phytochemicals Ltd. (Chendu, China).

\subsection{Animals and treatment protocol}

SPF-grade male Sprague-Dawley rats, weighing 120 to $130 \mathrm{~g}$ with the average age of four or five weeks, were purchased from Vital River Laboratory Animal Technology Co. Ltd. (Beijing, China). The experiment complied with the Animal Management Rule of the Ministry of Public Health, China, and the experimental protocol was approved by the Ethics Committee of Capital Medical University (No. AEEI-2015-042). All the animals were cared for in the Experimental Animal Center of Capital Medical University. During the entire experiment, the animals were housed in stainless cages (three rats per cage) at conventional controlled conditions (temperature of $23 \pm 2{ }^{\circ} \mathrm{C}$, relative humidity of $50 \pm 10 \%$, and $12 \mathrm{~h}$ light-dark cycle). They were given free access to the standard laboratory food and tap water.

The rats were acclimated to conditions for one week before the experiment and randomly assigned to the following 5 groups $(n=6)$ : normal control group (control), asthma model group (asthma), Dex group, icariin\&OA group, and co-administration of Dex and icariin\&OA group (Coadministration). OVA sensitization and challenge protocols were performed according to our previous methods. ${ }^{18}$ On days 1 and 8 , all rats except those in the control group were actively sensitized with intraperitoneal injection (ip) and subcutaneous injection of $1 \mathrm{mg}$ OVA and $100 \mu \mathrm{g}$ aluminum hydroxide in $1 \mathrm{~mL}$ sterile physiological saline. The OVAsensitized rats were exposed to $1 \%$ aerosolized OVA $(1 \mathrm{~g}$ OVA in $100 \mathrm{~mL}$ sterile physiological saline in an ultrasonic nebulizer) for $30 \mathrm{~min}$ from day 15 to day 35. Rats in the control group were exposed to sterile physiological saline only. The asthma group received no treatment; Dex and Coadministration groups received $5 \mathrm{mg} \mathrm{kg}{ }^{-1}$ Dex sodium phosphate injection (ip) (Rongsheng Pharmaceutical Co., Ltd, Henan, China); both icariin\&OA and Co-administration groups received $100 \mathrm{mg} \mathrm{kg}^{-1}$ herbal ingredients via intragastric administration (ig). All treatments were conducted from day 15 to 35 , once a day for 21 days.

On day 36 , all the rats were bled and sacrificed with anaesthesia of ethyl carbamate $24 \mathrm{~h}$ after the last OVA exposure. Blood samples were collected by abdominal aortic puncture. Lungs were lavaged 3 times with ice-cold saline $(3 \mathrm{~mL}, 3 \mathrm{~mL}$ and $4 \mathrm{~mL}$ ) using a tracheal cannula and a $5 \mathrm{~mL}$ polyethylene syringe. The cell-debris pellets of the bronchoalveolar lavage fluid (BALF) samples were collected after centrifugation. Lymphocytes were separated from peripheral blood (PB) and BALF samples by assay of rat lymphocyte separation solution (Tinjin Haoyang Biological Manufacture Co., Ltd., Tianjin, China) and then resuspended with $1 \mathrm{~mL}$ of $4 \%$ paraformaldehydephosphate buffer solution. 


\subsection{Apoptosis assay by flow cytometry (FCM)}

Apoptosis in CEM-C7 and CEM-C1 cells was detected using an Annexin-FITC apoptosis detection kit (MultiSciences Biotech Co., Ltd, Hangzhou, China). Cells were collected, washed and resuspended at $4 \times 10^{5}$ cells per $\mathrm{mL}$ in $500 \mu \mathrm{L}$ binding buffer containing $5 \mu \mathrm{L}$ Annexin V-FITC stock solution and $10 \mu \mathrm{L}$ propidium iodide (PI). After incubation for $5 \mathrm{~min}$ at room temperature in the dark, apoptosis of cells was detected by FCM. Apoptosis in lymphocytes of PB and BALF of rats was determined using the assay of TdT-dUTP terminal nick-end labeling (TUNEL, MBL Inc., Nagoya, Japan) for FCM according to the manufacturer's instruction. ${ }^{23}$ A FACS Calibur flow cytometer (BD Biosciences, San Jose, CA, USA) was used to determine the lymphocyte apoptosis level through mean fluorescence intensity (MFI).

\subsection{GR-mAb-FCM analysis and FITC labelled-Dex-FCM analysis}

Anti-GR mAb and anti-mouse PE labelled IgG (Abcam, Cambridge, UK) were used for the detection of GR protein expression. PE-labelled mouse IgG1 isotype (Abcam, Cambridge, UK) was used for the control samples. CEM-C7 and CEM-C1 cells were washed with PBS twice and resuspended in $\mathrm{T}$ liquid (3\% Triton-X 100 and 10\% normal goat serum) and incubated on ice for $10 \mathrm{~min}$. Resuspended lymphocytes in PB and BALF were washed with PBS twice and refixed in $100 \mu \mathrm{L}$ of $4 \%$ buffered paraformaldehyde for $30 \mathrm{~min}$ at $4{ }^{\circ} \mathrm{C}$. Nonspecific binding sites were blocked with $5 \%$ normal goat serum containing permeabilisation buffer for $30 \mathrm{~min}$. Cells were then incubated with $100 \mu \mathrm{L}$ permeabilisation buffer containing $50 \mu \mathrm{L}$ anti-GR mAb $(1: 100)$ or mouse IgG1 $(1: 100)$ for $60 \mathrm{~min}$, washed twice in the permeabilisation buffer, and then incubated with $100 \mu \mathrm{L}$ permeabilisation buffer containing goat anti-mouse IgG-PE (Caltag, Burlingame, CA, USA) for $60 \mathrm{~min}$. After extensive washing with the permeabilisation buffer to remove unbound secondary antibodies, cells were resuspended in $500 \mu \mathrm{L}$ fixation buffer. Cells were run on a FACS Calibur flow cytometer. ${ }^{24,25}$ The relative quantity of GR protein (mean fluorescence) was expressed as MFI.

Resuspended lymphocytes in PB and BALF of rats or CEM-C7 and CEM-C1 cells were washed with PBS and resuspended in $100 \mu \mathrm{L}$ PBS containing $2 \times 10^{-5}$ M FITC-Dex (Molecular Probe ${ }^{\circledR}$, Invitrogen, Carlsbad, CA, USA) for $60 \mathrm{~min}$ at $37{ }^{\circ} \mathrm{C}$ in the dark with gentle mixing every $10 \mathrm{~min}$. As controls, another tube was prepared adding a 500-fold excess amount of unlabelled Dex 10 min before FITC-Dex. Finally, cells were washed twice and resuspended in $300 \mu \mathrm{L}$ fixation buffer. Cell samples were run on a FACS Calibur flow cytometer. ${ }^{26}$ The relative quantity of GR binding (mean fluorescence) was expressed as MFI.

\subsection{Immunofluorometric assay (IF)}

CEM-C7 and CEM-C1 cells were fixed with 4\% paraformaldehyde at room temperature. For staining, the cells were rinsed three times with PBS ( 3 min each time). After the final centrifugation, the cells were slowly suspended by retaining about $50 \mu \mathrm{L}$ of liquid drip onto the slide, which was precooled for $10 \mathrm{~min}$ at $-20{ }^{\circ} \mathrm{C}$ to, as far as possible, evenly distribute the cells. The slide was baked for about $10 \mathrm{~min}$ and blocked by $2 \%$ BSA. Then, the cell was incubated with anti-GR $\alpha$ or GR $\beta$ antibodies (Abcam, Cambridge, UK) at a concentration of $1: 50$ at $4{ }^{\circ} \mathrm{C}$ overnight. After washing, the cells were incubated with FITC-conjugated goat anti-rabbit IgG (1:200 dilution) at room temperature for $1 \mathrm{~h}^{27}$

\subsection{Immunohistochemistry assay (IHC)}

GR $\alpha$, GR $\beta$ and HSP90 were identified in paraffin-embedded sections of the lung tissue by IHC staining with anti-GR $\alpha$ antibody, anti-GR $\beta$ antibody or HSP90 antibody (Abcam, Cambridge, UK) overnight at $4{ }^{\circ} \mathrm{C}$ at a concentration of $1: 100(\mathrm{GR} \alpha$ and HSP90) or $1: 200$ (GR $\beta$ ), followed by standard biotinstreptavidin-peroxidase immunostaining using a streptavidinperoxidase kit (Zhong Shan Golden Bridge Biotechnology Co., Ltd., Beijing, China) according to the instructions provided by the manufacturer. Staining was completed by incubation with diaminobenzidine chromogen solution at room temperature. All measurements were performed with a Nikon ECLIPSE 80i biomicroscope and NIS-Elements BR 3.2 image analysis system. Three random images within a lung sample were recorded and further analyzed using zoomed-in field at $400 \times$ magnification. We measured the integral optical density (IOD) of GR $\alpha$, GR $\beta$ and HSP90-positive cells under each examined field, and calculated the average number as the final result of the sample.

\subsection{Western blotting analysis}

Rat lung tissues were lysed on ice in RIPA lysis buffer with protease inhibitor cocktail for 15 min to extract total protein. Concentration of the protein was quantified by a quantitative bromochloroacetate (BCA) protein kit (Beijing Biosynthesis Biotechnology Co., Ltd., Beijing, China). The protein was mixed with loading buffer and boiled at $95{ }^{\circ} \mathrm{C}$ for $5 \mathrm{~min}$ to make it denatured. Equal amount of protein (30 $\mu \mathrm{g}$ per lane) was separated by $8 \%$ sodium dodecyl sulfatepolyacrylamide gel electrophoresis (SDS-PAGE) and transferred into $0.45 \mu \mathrm{m}$ polyvinylidene fluoride (PVDF) membranes. After blocking with 5\% nonfat-dried milk at room temperature for $2 \mathrm{~h}$, the membranes were incubated overnight at $4{ }^{\circ} \mathrm{C}$ with primary antibodies: rabbit polyclonal to HSP90 antibody ( $1: 5000)$, rabbit polyclonal to GR $\alpha$ antibody $(1: 2000)$, rabbit polyclonal to GR $\beta$ antibody $(1: 2000)$ and mouse monoclonal to $\beta$-actin antibody $(1: 2000)$. Membranes were detected with horseradish peroxidase-labeled goat anti-rabbit IgG $(1: 20000)$ or goat anti-mouse IgG $(1: 40000)$ as the secondary antibody for $1 \mathrm{~h}$. The protein band was visualized by an electrochemiluminescent (ECL) reagent and exposed to X-film. $\beta$-Actin was used for normalization. The sum-density of each protein band was measured by Image $\mathrm{J}$ software (National Institutes of Health, USA).

\subsection{Quantitative real-time PCR (qPCR)}

Total RNA was isolated from the lung tissue using TRIzol reagent (Life Technologies, Carlsbad, CA, USA) according to the manufacturer's recommendations, followed by purification 
Table 1 Primers used for qPCR analysis

\begin{tabular}{lll}
\hline Primer & Forward primer & Reverse primer \\
\hline HSP90 & CCTGGGAAGCCCCCG & TTGTAGACATGAGCAGAGAGCC \\
GR $\alpha$ & GCGACAGAAGCAGTTGAGTCATC & CCATGCCTCCACGTAACTGTTAG \\
GR $\beta$ & GCGCTTGAGGCTAAGATAGCT & CCCATGTTTCTGCCTCTTTCTTTG \\
$18 \mathrm{~S}$ & CCGGTACAGTGAAACTGCGA & GATAAATGCACGCGTTCCCC
\end{tabular}

with an RNeasy kit (Qiagen, Valencia, CA, USA) according to the manufacturer's manual. M-MLV reverse transcription was used to synthesize complementary DNA (cDNA). The qPCR amplification was performed using the SYBR-green detection of PCR products in real time with an ABI-7500 sequence detection system (Applied Biosystems, Foster City, CA, USA). The primers used in the qPCR analysis are presented in Table 1. The PCR program was performed for 40 cycles with each cycle consisting of $5 \mathrm{~min}$ of predenaturation at $94^{\circ} \mathrm{C}, 15 \mathrm{~s}$ of denaturation at $94{ }^{\circ} \mathrm{C}$, and $30 \mathrm{~s}$ of annealing at $60^{\circ} \mathrm{C}$. The melting curves for each PCR reaction were generated to ensure the purity of the amplification product. A no-template negative control was included in each experiment. Gene expression was quantified by means of the comparative $C_{\mathrm{t}}$ method $\left({ }^{\Delta \Delta} C_{\mathrm{t}}\right)$ and the relative quantification (RQ) was calculated as $2^{-\Delta \Delta C_{\mathrm{t}}}$. Relative mRNA levels of GR $\alpha$, GR $\beta$ and HSP90 were examined and normalized to $18 \mathrm{~S}$ mRNA expression in each sample.

\subsection{Statistical analysis}

Results of all measurements were presented as standard deviation (SD). The data analysis was performed using the SPSS 13.0 software (SPSS Inc., Chicago, USA). All of the data were tested and cleared for normality using the Kolmogorov-Smirnov test. A one-way analysis of variance (ANOVA) was performed to determine whether there were statistically significant differences $(P<$ 0.05) among the experimental groups. The least significant difference (LSD) test when the variances were equal or Tamhane's T2 test when the variances were unequal was used for comparisons between individual groups and to determine the means that differed statistically significantly $(P<0.05)$.

\section{Results}

\subsection{Combination of icariin and OA sensitizes GC-resistant CEM-C1 cells to Dex-induced apoptosis}

GCs are well recognized to negatively impact the development and function of $\mathrm{T}$ cells in the immune system by inducing apoptosis. ${ }^{28}$ This study investigated Dex-induced apoptosis in both GC-sensitive CEM-C7 and GC-resistant CEM-C1 cells by FCM. As shown in Fig. 1, compared with four drug control treatments, Dex, icariin, OA and icariin\&OA, co-administration (combination of Dex and icariin\&OA) increased the apoptotic rate from 26.43\% (Dex), 10.87\% (icariin), 12.01\% (OA), and $17.98 \%$ (icariin\&OA) to $39.33 \%$ in CEM-C7 cells, and from 4.90\% (Dex), 6.92\% (icariin), 7.31\% (OA), and 8.70\% (icariin\&OA) to $30.13 \%$ in CEM-C1 cells (all $P<0.01$ ). These results indicated that combination of icariin and OA augmented Dex- induced apoptosis not only in GC-sensitive CEM-C7 cells, but also in GC-resistant CEM-C1 cells.

\subsection{Combination of icariin and OA modulates Dex-induced lymphocyte apoptosis in asthmatic rats}

GCs have been used for decades to therapeutically modulate inflammation. Both anti-inflammatory effect and the side effects of GCs are related to inducing apoptosis in autologous mixed lymphocytes. ${ }^{29,30}$ Therefore, the level of lymphocyte apoptosis could indicate the sensitivity of anti-inflammatory effects of GCs. In this study, FCM was performed to determine lymphocyte apoptosis in PB and BALF with TUNEL assay. Rats in Dex group presented higher lymphocyte apoptosis in $\mathrm{PB}$ than those in the control or asthma groups $(P<0.05)$. Combination of icariin and OA could effectively reduce lymphocyte apoptosis in $\mathrm{PB}$ to nearly normal levels $(P<0.05)$. The results indicated that co-administration of the herbal ingredients and Dex could protect blood lymphocyte from excessive apoptosis (Fig. 2).

\subsection{Combination of icariin and OA augmented Dex-induced activation of GR in CEM-C7 and CEM-C1 cells}

The up-regulation of GR has been suggested as an essential step in GC-induced apoptosis of many types of cells. ${ }^{31}$ The abnormalities of GR seem to be related to GCR. ${ }^{32}$ With anti-GR mAb and FITC-labelled Dex, FCM was used to assess GR protein expression and GR binding in both GC-sensitive CEM-C7 and GC-resistant CEM-C1 cells. As shown in Fig. 3, GR protein greatly increased, while GR binding was not differential after Dex administration in both GC-sensitive CEM-C7 and GCresistant CEM-C1 cells, indicating that the sufficiency of GR content could not induce the corresponding function of GC. Compared with Dex, GR protein and GR binding in the coadministration group significantly increased in both types of cells $(P<0.01)$, which indicated that co-administration of the herbal ingredients and Dex markedly augmented Dex-induced activation of GR.

\subsection{Effect of combination of icariin and OA on Dex-induced activation of GR in asthmatic rats}

We further confirmed the effects of the herbal ingredients on Dex-induced activation of GR in asthmatic rats. As shown in Fig. 4A, GR protein and GR binding in PB lymphocytes greatly decreased following repeated Dex administration $v s$. control group $(P<0.01)$, indicating insufficiency of GR function. Compared with the Dex group, significant increase in GR 
A

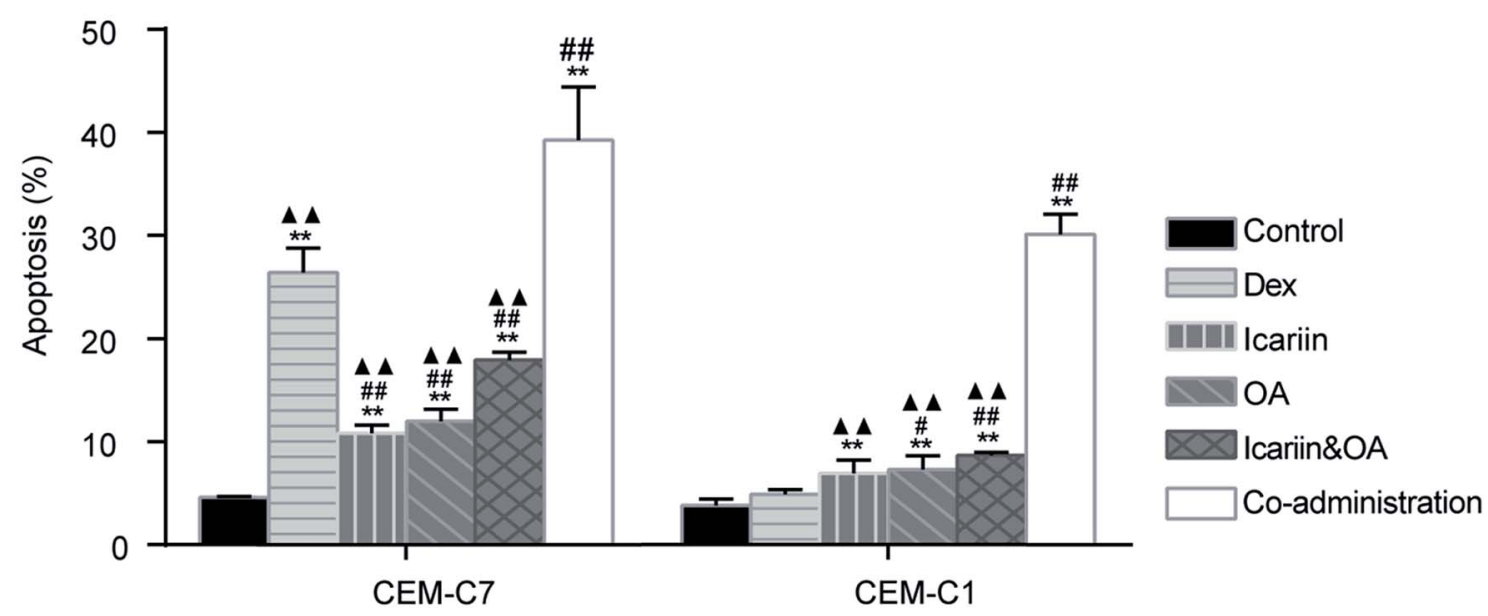

B
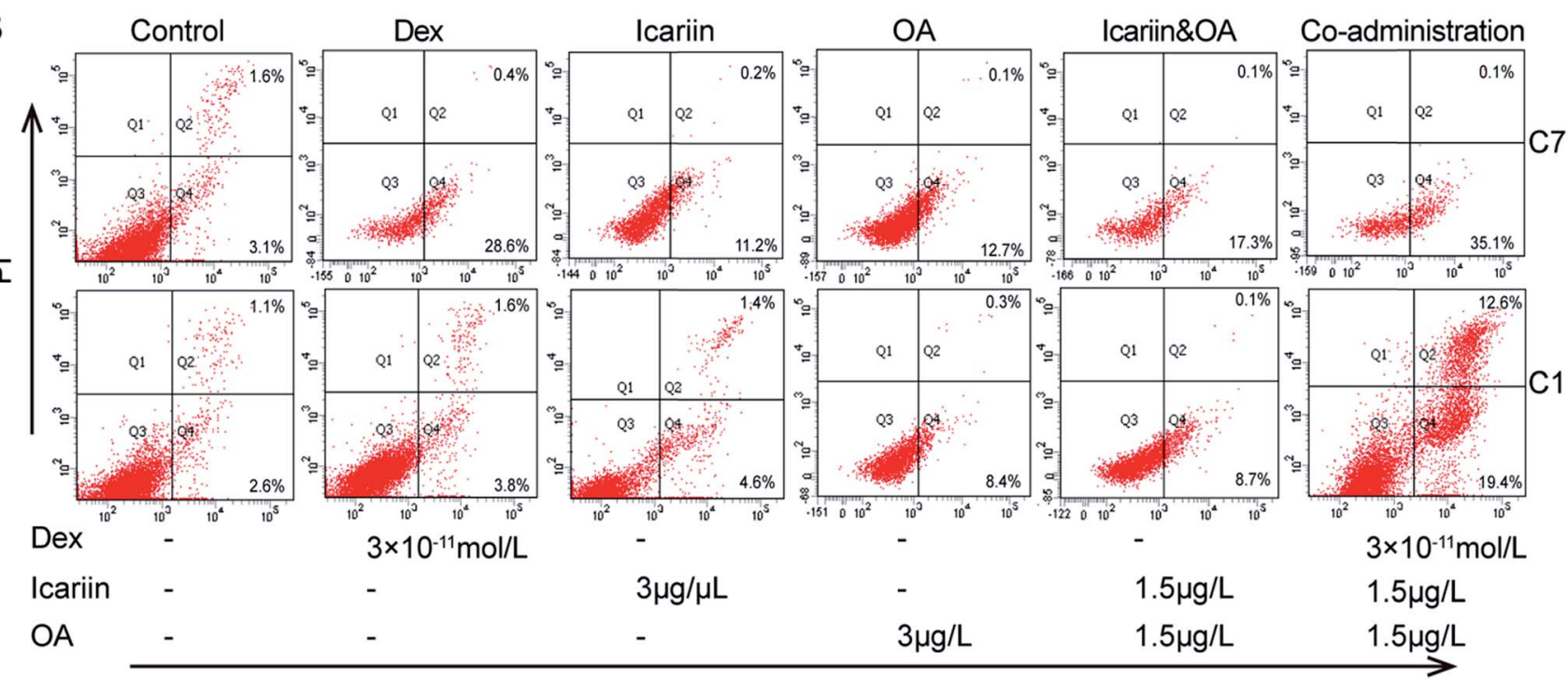

Annexin V-FITC

Fig. 1 Combination of icariin and oleanolic acid (OA) enhanced dexamethasone (Dex)-induced apoptosis in both GC-sensitive CEM-C7 and GCresistant CEM-C1 cells. The percentage of apoptotic cells was determined by Annexin V-FITC/PI staining and flow cytometry (FCM). (A) Levels of apoptosis rates in both GC-sensitive CEM-C7 and GC-resistant CEM-C1 cells. Percentages of each gated fraction (\%) are marked on the figures. (B) Representative photographs of apoptosis by FCM. Mean $\pm \mathrm{SD}, n=3$. ${ }^{* *} P<0.01 \mathrm{vs}$. control; ${ }^{*} P<0.05$, ${ }^{\# \#} P<0.01 \mathrm{vs}$. Dex; ${ }^{\boldsymbol{\Delta}} P<0.01 \mathrm{vs}$. coadministration.

protein and GR binding were noticed in the co-administration group $(P<0.05$ or $P<0.01)$, which indicated that coadministration of Dex and the herbal ingredients could markedly augment Dex-induced activation of GR in $\mathrm{PB}$ lymphocytes. As shown in Fig. 4B, GR binding in BALF lymphocytes remarkably decreased $(P<0.01)$, while GR protein could not be differentiated after repeated Dex administration compared with that in the control or asthma groups. Significant increase in GR binding of BALF lymphocyte was noticed in the co-administration group $v s$. Dex group $(P<0.01)$, indicating that co-administration of Dex and the herbal ingredients could markedly increase the binding capacity between GC and GR to protect Dex-induced impairment of GR activation.

\subsection{Combination of icariin and OA regulates Dex-induced GR isoforms in CEM-C7 and CEM-C1 cells}

In the processes of alternative splicing of GR, 2 major mRNA isoforms, GR $\alpha$ and GR $\beta$, are generated. GR $\alpha$ is ubiquitously expressed and is responsible for the induction and repression of target genes. GR $\beta$ acts as a dominant negative inhibitor of GR $\alpha$ mediated transactivation and transrepression. Increased expression of GR $\beta$, which competes with and thus inhibits activated GR $\alpha$, can cause GC resistance. ${ }^{33}$ In this study, protein expressions of GR $\alpha$ and GR $\beta$ in both GC-sensitive CEM-C7 and GC-resistant CEM-C1 cells were tested by IF, and an altered ratio of GR $\beta$ to GR $\alpha$ was calculated to evaluate the regulation effect of combination of icariin and OA on Dex-induced GR isoforms. As shown in Fig. 5, GR $\alpha$ protein in the CEM-C7 cells significantly 
A

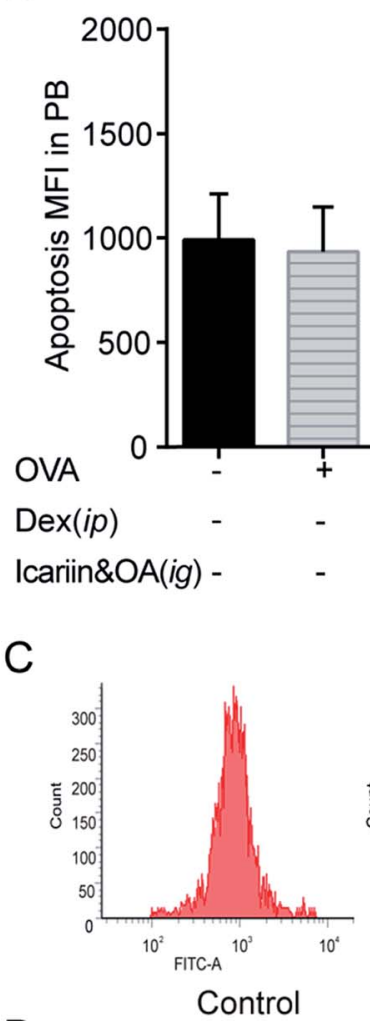

D

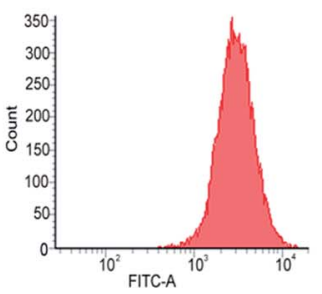

Control

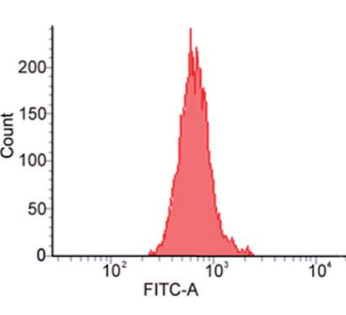

Asthma

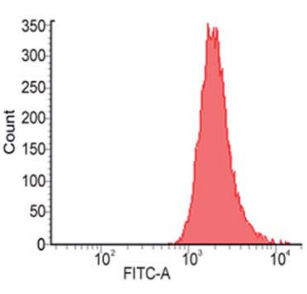

Asthma

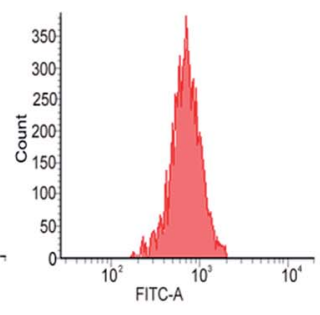

Dex

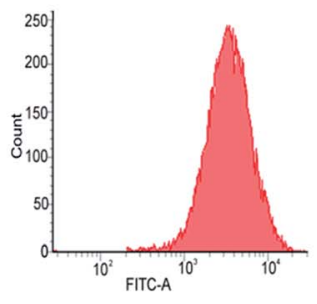

Dex
B

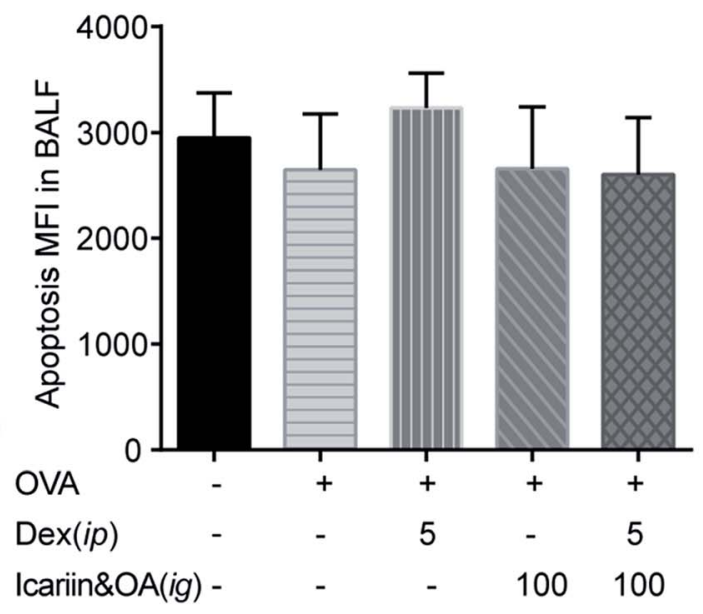

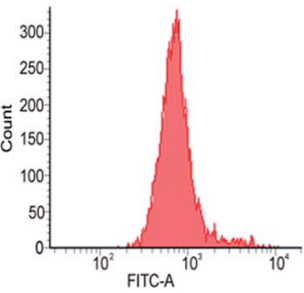

Co-administration

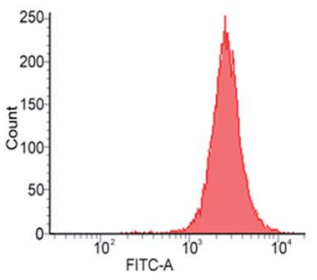

Icariin\&OA

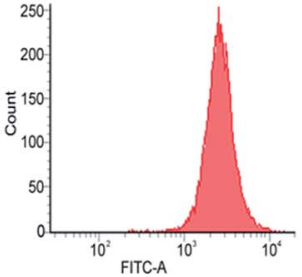

Co-administration

Fig. 2 Combination of icariin and oleanolic acid (OA) regulated dexamethasone (Dex)-induced lymphocyte apoptosis in asthmatic rats. Viability of the levels of lymphocyte apoptosis in peripheral blood (PB, A) and bronchoalveolar lavage fluid (BALF, B) were detected by flow cytometry (FCM) with TUNEL assay and expressed as mean fluorescence intensity (MFI). Representative photographs of lymphocyte apoptosis in PB (C) and BALF (D) by FCM. Mean $\pm \mathrm{SD}, n=6$. ${ }^{*} P<0.05$ vs. control; ${ }^{\#} P<0.05$ vs. asthma; ${ }^{\mathbf{\Delta}} P<0.05, \boldsymbol{\Delta} \sim<0.01$ vs. Dex.

increased and GR $\beta$ protein in the CEM-C1 cells significantly increased after Dex administration vs. control group; then, the ratio of GR $\beta$ to GR $\alpha$ decreased in the $\mathrm{CEM}-\mathrm{C} 7$ cells and increased in the CEM-C1 cells. This was consistent with the conclusion that GR $\beta$ can cause GCR. Compared with the Dex group, co-administration treatment increased GR $\alpha$ protein in both GC-sensitive CEM-C7 and GC-resistant CEM-C1 cells $(P<$ 0.01 ) and decreased GR $\beta$ protein and ratio of GR $\beta$ to GR $\alpha$ in the CEM-C1 cells. These results suggest that combination of icariin and OA rebalances Dex-induced GR $\beta /$ GR $\alpha$ in GC-sensitive CEMC7 and GC-resistant CEM-C1 cells.

\subsection{Combination of icariin and OA regulates Dex-induced GR isoforms in asthmatic rats}

Protein and mRNA expressions of GR $\alpha$ and GR $\beta$ in the lung tissue of asthmatic rats were tested by IHC, Western blotting and qPCR. After repeated Dex administration, GR $\alpha$ protein and mRNA significantly decreased $(P<0.05$ or $P<0.01)$, while GR $\beta$ protein and mRNA increased $v s$. that in control group $(P<0.05$ or $P<0.01)$. Compared with the Dex group, significant increments were noticed in GR $\alpha$ mRNA and protein and decrements were noticed in GR $\beta$ mRNA and protein in the coadministration group $(P<0.05$ or $P<0.01)$. These results suggest that combination of icariin and OA regulates GR isoforms in the rat asthmatic model with the treatment of Dex. (Fig. 6)

\subsection{Combination of icariin and OA up-regulates Dex- induced HSP90 in asthmatic rats}

HSP90 associates selectively with unliganded GR, and the appropriate folding of GR depends on direct interactions with the chaperone, HSP90. ${ }^{34}$ Dissociation of GR-associated proteins 
A

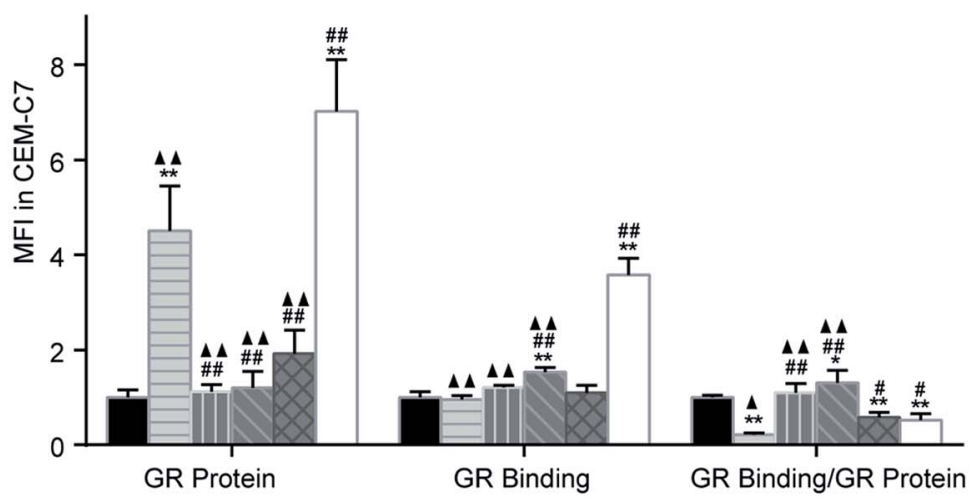

B
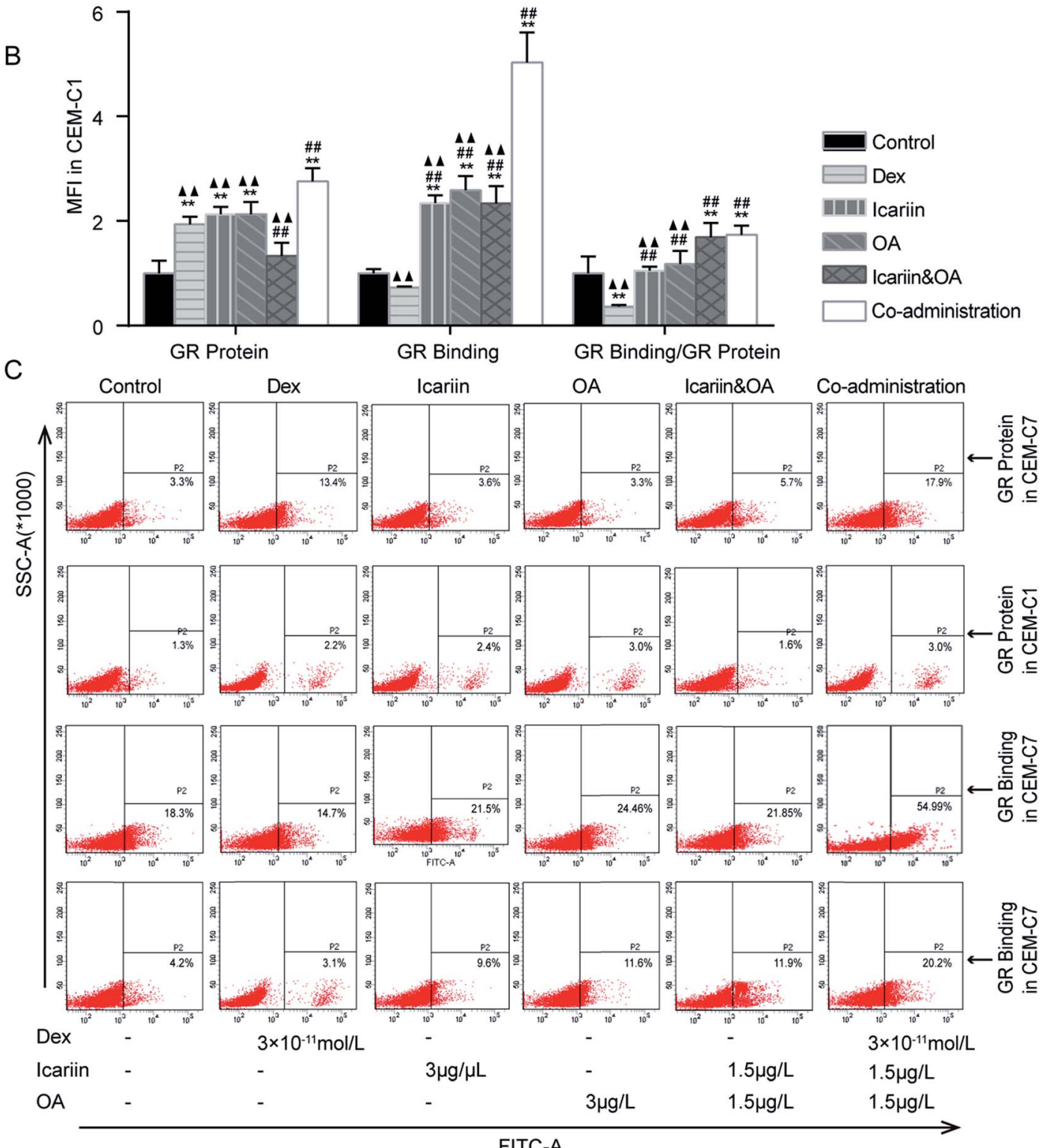

Fig. 3 Combination of icariin and oleanolic acid (OA) augmented dexamethasone (Dex)-induced activation of GR in CEM-C7 and CEM-C1 cells. GR protein and GR binding were detected by flow cytometry (FCM) and expressed as mean fluorescence intensity (MFI). Fold changes of GR protein, GR binding and GR binding/GR protein relative to control group in CEM-C7 cell (A) and CEM-C1 cell (B). (C) Representative photographs of GR protein and GR binding in CEM-C7 and CEM-C1 cells; the percentage of positive cells of GR protein and FITC-dexamethasone (Dex) was determined relative to total cells. Mean $\pm \mathrm{SD}, n=3 . * P<0.05, * * P<0.01$ vs. control; ${ }^{\#} P<0.05,{ }^{\# \#} P<0.01$ vs. Dex; ${ }^{\wedge} P<0.05,{ }^{\wedge}{ }^{\wedge} P<0.01$ vs. coadministration. 
A

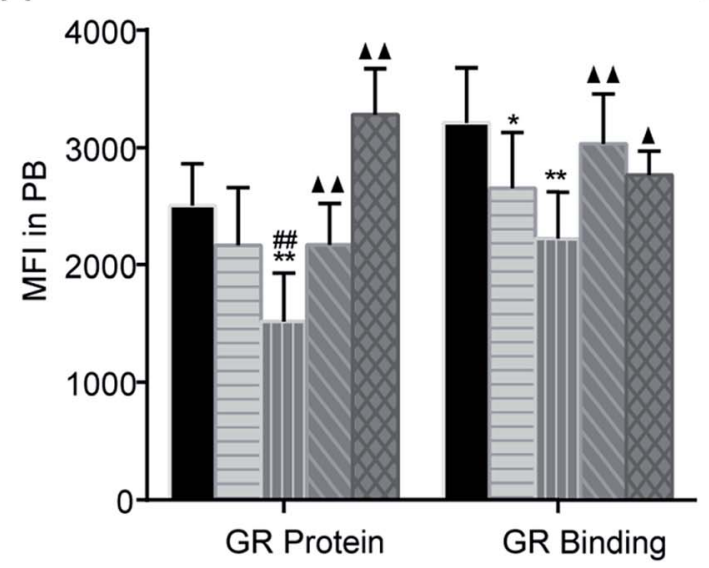

B

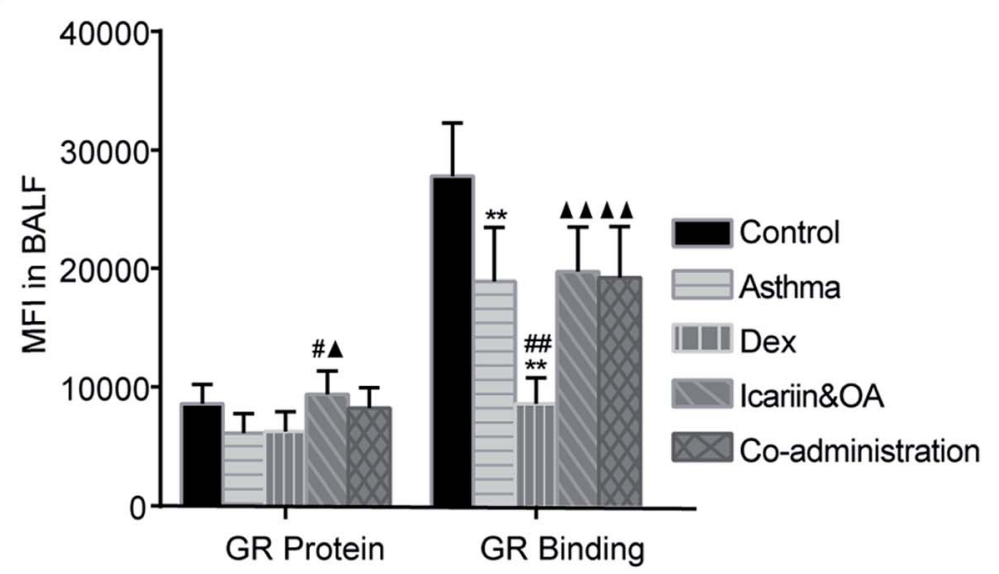

C


5
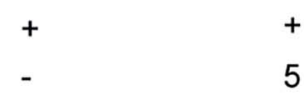

100

$\begin{array}{cc}5 & \mathrm{mg} / \mathrm{kg} \\ 100 & \mathrm{mg} / \mathrm{kg}\end{array}$

Fig. 4 Effect of combination of icariin and oleanolic acid (OA) on dexamethasone (Dex)-induced activation of GR in asthmatic rats. Levels of GR protein and GR binding in lymphocytes of peripheral blood (PB, A) and bronchoalveolar lavage fluid (BALF, B) by flow cytometry (FCM) and expressed as mean fluorescence intensity (MFI). (C) Representative photographs of GR protein and GR binding in lymphocyte of PB and BALF by FCM. Mean \pm SD, $n=6$. $* P<0.05, * * P<0.01$ vs. control; ${ }^{\#} P<0.05$, ${ }^{\#} P<0.01$ vs. asthma; $P<<0.05, \Delta \Delta^{*} P<0.01$ vs. Dex.

accompanies hormone binding and leads to the exposure of its various functional domains. Although an association with HSP90 presumably masks the GR nuclear localization signal sequence, the recent demonstration of the co-import of GR and HSP90 into cell nuclei has led to the hypothesis that HSP90 facilitates GR interactions with the nuclear transport machinery. To gain insight into the mechanisms of GC regulation in a physiological context, the level of HSP90 in the lung tissues of asthmatic rats was examined by IHC, Western blotting and qPCR. The plot in Fig. 7 shows that the expressions of HSP90 protein and mRNA in the Dex group significantly decreased as compared to the control group $(P<0.05$ or $P<$ 
A

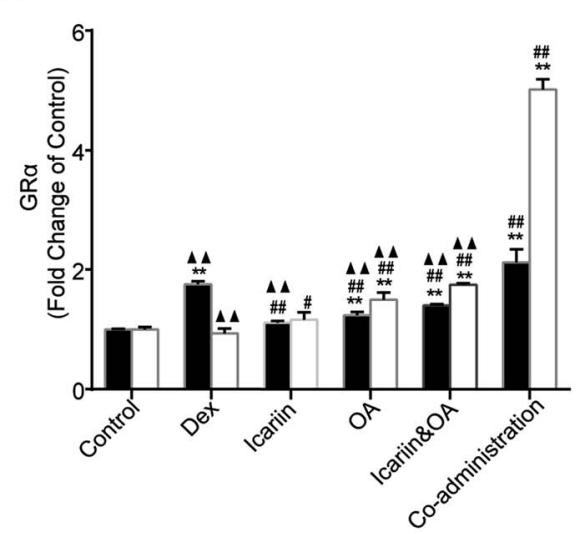

B

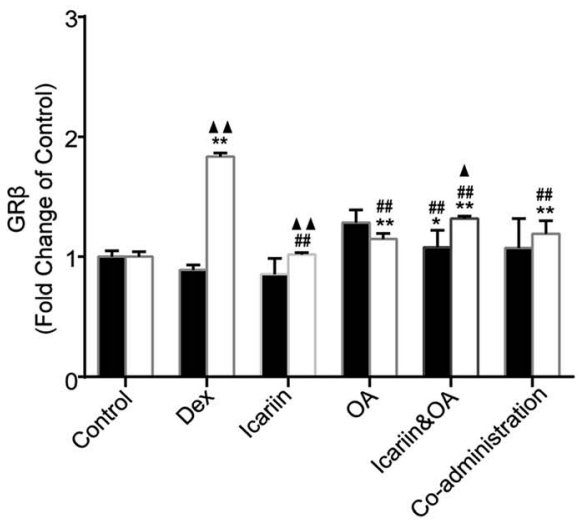

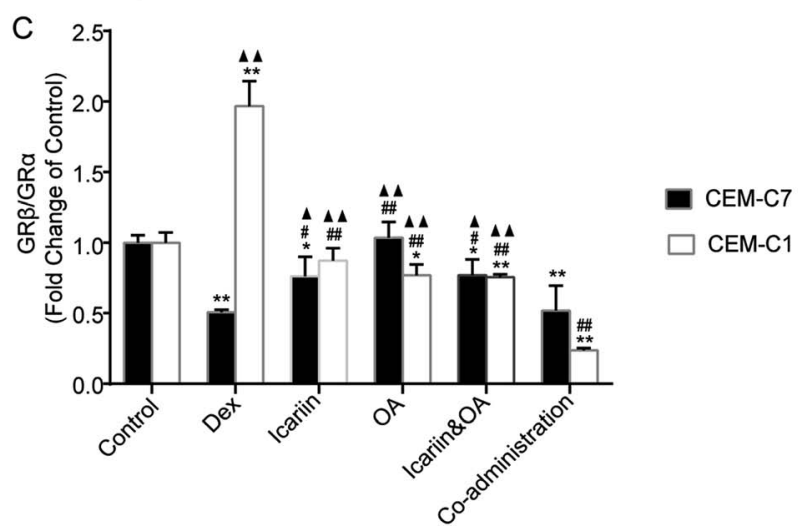

Fig. 5 Combination of icariin and oleanolic acid (OA) regulated dexamethasone (Dex)-induced GR isoforms in both GC-sensitive CEM-C7 and GC-resistant CEM-C1 cells. Fold changes of GR $\alpha$ protein (A), GR $\beta$ protein (B) and GR $\beta / G R \alpha(C)$ relative to control group in CEM-C7 and CEM-C1 cells by immunofluorometric assay. Mean $\pm \mathrm{SD}, n=3$. ${ }^{*} P<0.05,{ }^{* *} P<0.01 \mathrm{vs}$. control; ${ }^{\#} P<0.05,{ }^{\# \#} P<0.01 \mathrm{vs}$. Dex; $P<0.05, \boldsymbol{\Delta} \mathbf{\Delta} P<0.01 \mathrm{vs}$. co-administration.

0.01). In addition, compared to the Dex group, the expressions of protein and mRNA of HSP90 in the co-administration group significantly increased $(P<0.05$ or $P<0.01)$. It could be inferred that the regulation mechanisms of the herbal ingredients on GC sensitivity were associated with the up-regulation of HSP90 expression.

\section{Discussion}

Because GCR occurs in multiple inflammatory and autoimmune diseases, it is widely accepted that GCR is a heterogeneous phenomenon with many underlying mechanisms. ${ }^{35}$ Many different molecular mechanisms of GCR have now been elucidated, but GR protein down-regulation can be the result of many different mechanisms of GCR. ${ }^{7}$ In our previous research, we demonstrated that the decoction and active ingredients (total flavonoids and triterpenoids) of EF and LLF could prevent the decrease of mRNA and protein expression of GR induced by Dex or Bun in asthmatic rats. ${ }^{14,15}$ We speculate that combination of icariin and $\mathrm{OA}$, agents extracted from $\mathrm{EF}$ and LLF, respectively, has the function of protecting GR. Icariin possesses extensive therapeutic effects, such as protecting neurons from injury, regulating nuclear receptors, improving sexual dysfunction and bone morphogenesis, as well as anti- inflammation, anti-tumor and anti-depression functions. ${ }^{36} \mathrm{OA}$ can protect against chemically induced liver injury and exhibits anti-inflammatory and anti-hyperlipidemic properties, antitumor promotion, toxicant activation inhibition and body defense system enhancement. ${ }^{37,38}$ However, combination of icariin and $\mathrm{OA}$, as an agent to revert GCR, has not been explored yet.

Lymphocytes, particularly $\mathrm{T}$ cells, are the best candidates for cellular and molecular targets of GCs. GCs induce apoptosis in $\mathrm{T}$ cells and are potent suppressors of cytokine production in $\mathrm{T}$ cells. $^{39}$ In addition, GCs stimulates apoptosis in all B-cell developmental subsets. ${ }^{40}$ Several animal models have been produced that have deleted the GR specifically in $\mathrm{T}$ cells, rendering them resistant to GC-induced apoptosis and elucidating the role of GC signaling in T-cell development. ${ }^{27,41}$ Our results show that combination of icariin and OA sensitized GCresistant CEM-C1 cells to Dex-induced apoptosis. Interestingly, combination of icariin and OA has no influence on Dex-induced lymphocyte apoptosis of BALF in asthmatic rats after repeated Dex administration while effectively reducing lymphocyte apoptosis in PB. It is possible that complex microenvironmental factors influence the sensitivity of GCs to lymphocytes in vivo.

GC insensitivity can be primarily caused by problems in the GR protein itself. Alterations in the GR expression that mediate 


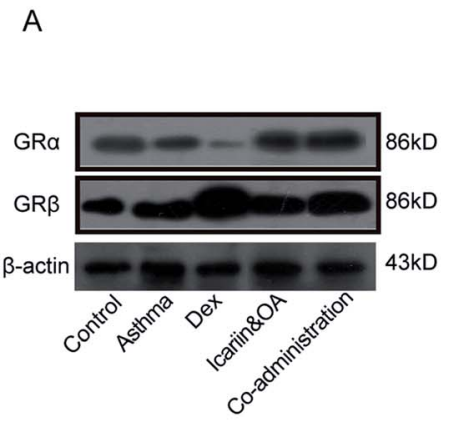

B

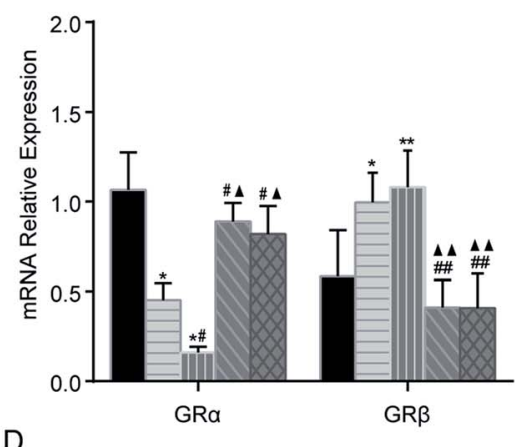

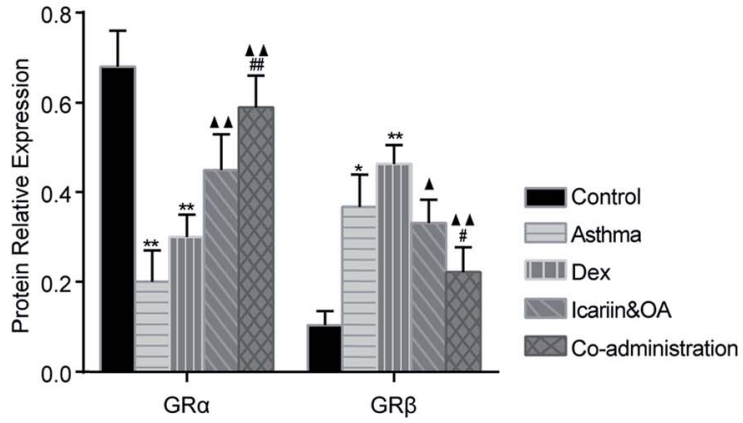

C
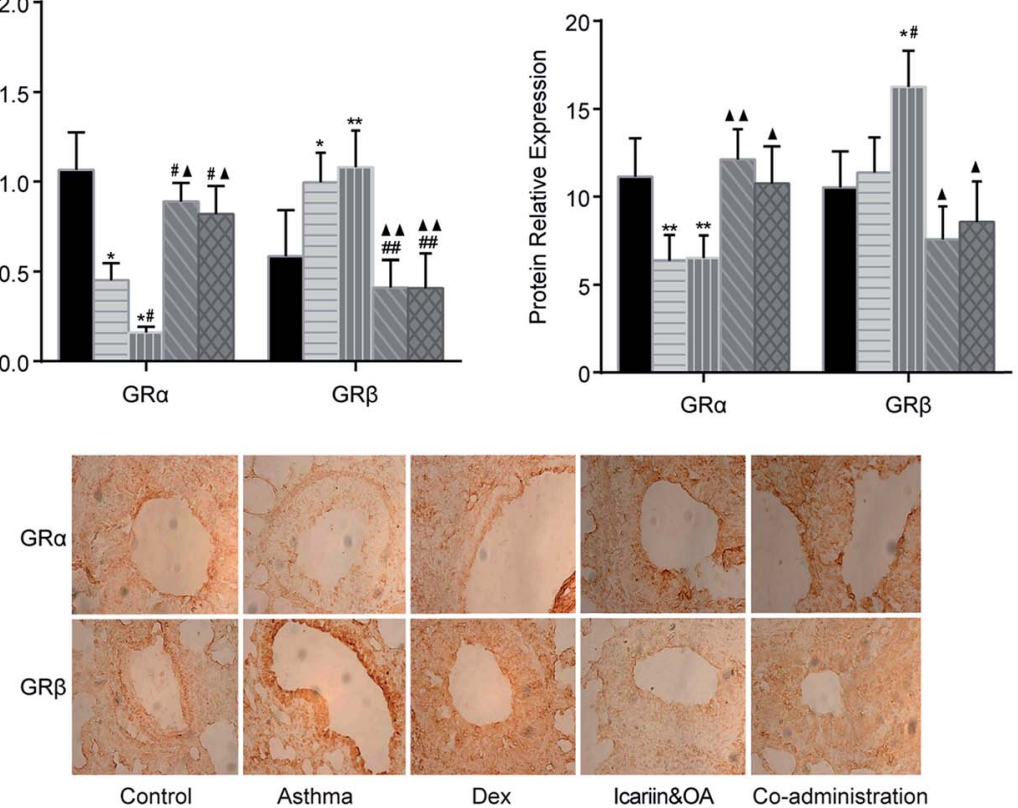

Fig. 6 Combination of icariin and oleanolic acid (OA) regulated dexamethasone (Dex)-induced GR isoforms in asthmatic rats. (A) GR $\alpha$ and GR $\beta$ proteins in lung tissues of the rat asthmatic model were detected by western blotting. (B) mRNA expressions of GR $\alpha$ and GR $\beta$ in lung tissues of the rat asthmatic model were detected by quantitative real-time PCR (qPCR). (C) GR $\alpha$ and GR $\beta$ proteins in lung tissues of the rat asthmatic model were detected by immunohistochemistry assay (IHC). (D) Representative photographs of GR $\alpha$ and GR $\beta$ protein expression in lung tissues by IHC. Mean $\pm \mathrm{SD}, n=6$. ${ }^{*} P<0.05,{ }^{*} P<0.01$ vs. control; ${ }^{\#} P<0.05,{ }^{\# \#} P<0.01$ vs. asthma; $P<0.05,{ }^{\wedge} \Delta<<0.01$ vs. Dex.

GC actions are one of the potential mechanisms that would explain reduced sensitivity of GC. Qualitative and quantitative abnormalities in GR binding to GCs have been described in the lymphocytes of patients with GC-resistant asthma or even in asthma in general. ${ }^{42}$ Reduction of GR protein and mRNA expression in the lungs of asthmatic mice has been reported. ${ }^{43}$ In the present study, we found that Dex induced significant increase in GR protein in GC-sensitive CEM-C7 and GC-resistant CEM-C1 cells, with the former being much stronger. However, no significant up-regulation of GR binding was noticed in the CEM-C7 and CEM-C1 cells. In vivo, GR protein in PB and GR binding in PB and BALF significantly decreased in asthmatic rats treated with Dex, which suggested that repeated Dex administration could induce GC insensitivity. Combination of icariin and OA could clearly increase GR protein and GR binding in vivo and in vitro to improve the sensitivity to GC.

GR gene expresses 2 splicing isoforms depending on the use of alternative exons $9 \alpha$ or $9 \beta .^{44}$ A less-abundant GR $\beta$ has a truncated ligand binding domain, does not bind GCs, and is found to be a dominant negative inhibitor of classic GR $\alpha .{ }^{45} \mathrm{An}$ association between GC insensitivity and increased GR $\beta$ expression has been reported in asthma and other diseases. ${ }^{46,47}$ It has been proposed that GCR could result from the imbalance between GR $\alpha$ and GR $\beta$, though there is a lack of information on whether the GR $\alpha / G R \beta$ ratio determines the level of GC responsiveness. ${ }^{48}$ In addition, it has been shown that GR $\beta$ does not interfere with GR-mediated transrepression and excess GR $\alpha$ appears to overcome its inhibitory action. ${ }^{49}$ In the present study, we found that Dex induced a significant increase in GR $\alpha$ protein in the CEM-C7 cells, while in the CEM-C1 cells, Dex induced a significant increase in GR $\beta$ protein. Then, the ratio of GR $\beta$ to GR $\alpha$ decreased in the CEM-C7 cells and increased in the CEM$\mathrm{C} 1$ cells. In vivo, GR $\alpha$ protein and mRNA significantly decreased, while GR $\beta$ increased in asthmatic rats after treatment with Dex for 21 days. It is suggested that repeated Dex administration can increase GR $\beta$ expression, further inhibiting the function of 


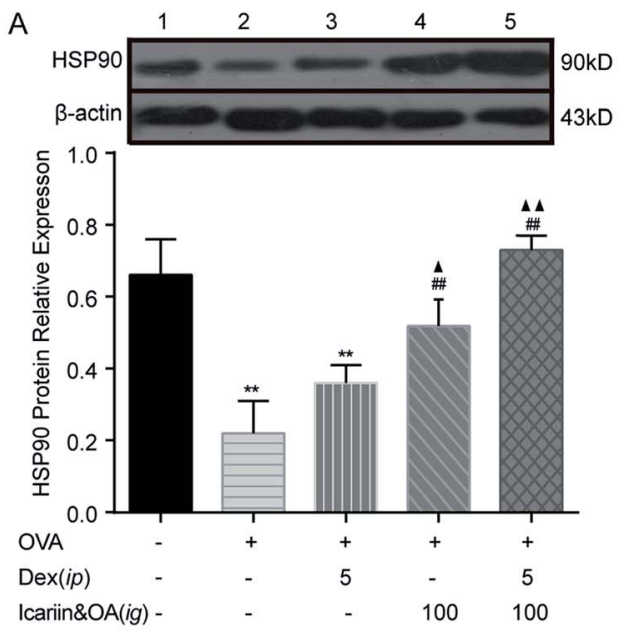

\section{B}

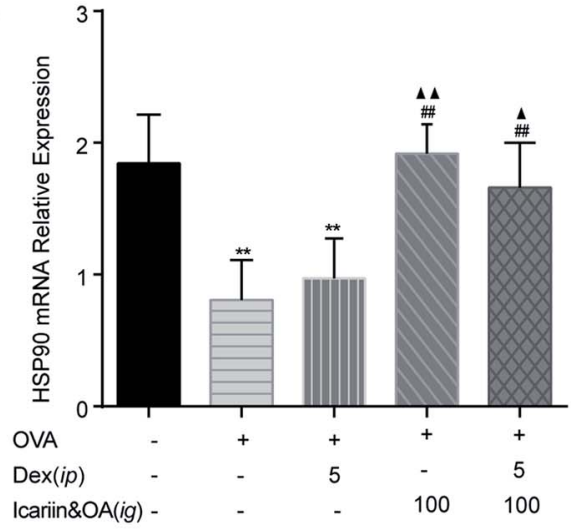

C
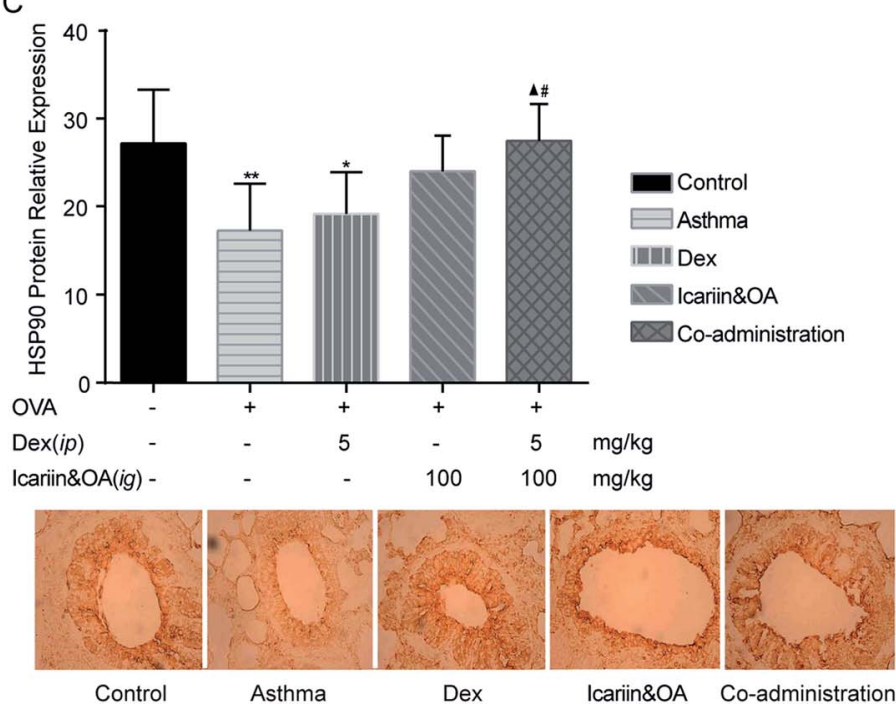

Fig. 7 Combination of icariin and oleanolic acid (OA) up-regulated dexamethasone (Dex)-induced HSP9O in asthmatic rats. (A) HSP90 protein in lung tissues of the rat asthmatic model was detected by western blotting. (B) HSP9O mRNA in lung tissues of the rat asthmatic model was detected by quantitative real-time PCR (qPCR). (C) HSP90 protein in lung tissues of the rat asthmatic model was detected by immunohistochemistry assay $(\mathrm{IHC}) .1=$ control; $2=$ asthma; $3=$ Dex; $4=$ icariin\&OA; $5=$ Co-administration. Mean $\pm \mathrm{SD}, n=6 . * P<0.05, * * P<0.01$ vs. control; ${ }^{\#} P<0.05,{ }^{\# \#} P<0.01$ vs. asthma; $\Delta P<0.05, \Delta \wedge<0.01$ vs. Dex.

GR $\alpha$, and lead to a decrease in GC sensitivity or an increase in the possibility of GCR. Combination of icariin and OA with Dex increased GR $\alpha$ expression and decreased GR $\beta$ expression, so that the imbalance of GR $\beta / \mathrm{GR} \alpha$ could be corrected in vivo and in vitro. It could be deduced that the possible mechanism of combination of icariin and OA to revert GCR is related to adjusting GR isoforms, including up-regulating the mRNA and protein expressions of GR $\alpha$, down-regulating the mRNA and protein expressions of GR $\beta$ to suppress the combination between GC and GR $\alpha$, and restoring the appropriate ratio of GR $\beta / \mathrm{GR} \alpha$.

In the cytoplasm, the inactive form of GR appears to be bound to HSP90. This interaction facilitates binding of GC to GR and depends on the relative amounts of the interacting components, GR and HSP90. HSP90 content can confer tissue specificity and sensitivity to GCs. ${ }^{50,51}$ Abnormal expression of HSP90 leads to the inhibition of GR translocation to the nucleus and reduction in its transcription. ${ }^{52}$ To gain insight into the mechanisms of GC regulation in a physiological context, the level of HSP90 in lung tissues of asthmatic rats was examined. We found that HSP90 protein and mRNA significantly decreased in the asthmatic rats after repeated Dex administration, and the combination of icariin and OA up-regulated Dexinduced HSP90 inhibition. It could be inferred that the regulation mechanisms of the herbal ingredients on GCR were associated with the up-regulation of HSP90 expression.

\section{Conclusions}

In summary, our study suggests that combination of icariin and OA could revert GCR through regulating lymphocyte apoptosis and GR isoforms and augmenting GR binding and HSP90 expression, and this could be a valuable and affordable approach for GCR in the future. 


\section{Abbreviations}

$\begin{array}{ll}\text { BALF } & \text { Bronchoalveolar lavage fluid } \\ \text { Dex } & \text { Dexamethasone } \\ \text { EF } & \text { Epimedii folium } \\ \text { FCM } & \text { Flow cytometry } \\ \text { FITC } & \text { Fluorescein isothiocyanate } \\ \text { GC } & \text { Glucocorticoid } \\ \text { GCR } & \text { Glucocorticoid resistance } \\ \text { GR } & \text { Glucocorticoid receptor } \\ \text { HSP90 } & \text { Heat shock protein 90 } \\ \text { Ig } & \text { Intragastric administration } \\ \text { IHC } & \text { Immunohistochemistry } \\ \text { IOD } & \text { Integral optical density } \\ \text { Ip } & \text { Intraperitoneal injection } \\ \text { LLF } & \text { Ligustri lucidi fructus } \\ \text { MFI } & \text { Mean fluorescence intensity } \\ \text { OA } & \text { Oleanolic acid } \\ \text { OVA } & \text { Ovalbumin } \\ \text { PB } & \text { Peripheral blood } \\ \text { PE } & \text { Phycoerythrin } \\ \text { qPCR } & \text { Quantitative real-time PCR } \\ \text { TCM } & \text { Traditional Chinese medicine } \\ \text { TUNEL } & \text { TdT-dUTP terminal nick-end labeling } \\ & \end{array}$

\section{Author contributions}

Renhui Liu and Xiufeng Tang wrote the manuscript. Xiufeng Tang, Xiaoxi Li, Yuheng Chen, Yingying Gao and Ping Yu performed the experiments. Liping $\mathrm{Xu}$ and Renhui Liu conceived and designed the experiments.

\section{Conflicts of interest}

The authors declare no conflict of interest.

\section{Acknowledgements}

This research was supported by Natural Science Foundation of China (Grant No. 81373814 and 81673993), the Development of High-Caliber Talents Project of Beijing Municipal Institutions (Grant No. CIT\&TCD201504097), and the Planned Project on Beijing Traditional Chinese Medicine Inheritance of " $3+3$ Programme” of the Beijing Chinese Medicine Administration Bureau (Grant No. 2012-SZ-C-42).

\section{References}

1 J. A. Beach, L. J. Nary, R. Hovanessian and R. D. Medh, Biochem. Biophys. Res. Commun., 2014, 451, 382-388.

2 K. Dendoncker and C. Libert, Cytokine Growth Factor Rev., 2017, 35, 85-96.

3 C. Heuck, O. D. Wolthers, M. Hansen and G. Kollerup, Steroids, 1997, 62, 659-664.

4 E. W. Zöllner, C. Lombard, U. Galal, S. Hough, E. Irusen and E. J. Weinberg, Pediatr. Endocrinol. Metab., 2011, 24, 529-534.
5 K. N. Priftis, A. Papadimitriou, M. B. Anthracopoulos, A. Fretzayas and G. P. Chrousos, NeuroImmunoModulation, 2009, 16, 333-339.

6 P. J. Barnes and I. M. Adcock, Lancet, 2009, 373, 1905-1917.

7 M. Zen, M. Canova, C. Campana, S. Bettio, L. Nalotto, M. Rampudda, R. Ramonda, L. Iaccarino and A. Doria, Autoimmun. Rev., 2011, 10, 305-310.

8 S. Schmidt, J. Rainer, C. Ploner, E. Presul, S. Riml and R. Kofler, Cell Death Differ., 2004, 11, S45-S55.

9 M. J. Schaaf and J. A. Cidlowski, J. Steroid Biochem. Mol. Biol., 2002, 83, 37-48.

10 K. Pazdrak, C. Straub, R. Maroto, S. Stafford, W. I. White, W. J. Calhoun and A. Kurosky, J. Immunol., 2016, 197, 3782-3791.

11 P. J. Barnes, Handb. Exp. Pharmacol., 2017, 237, 93-115.

12 T. L. Green, S. M. Leventhal, D. Lim, K. Cho and D. G. Greenhalgh, Shock, 2017, 47, 148-157.

13 A. D. Wallace and J. A. J. Cidlowski, Biol. Chem., 2001, 276, 42714-42721.

14 R. D. Medh, M. S. Webb, A. L. Miller, B. H. Johnson, Y. Fofanov, T. Li, T. G. Wood, B. A. Luxon and E. B. Thompson, Genomics, 2003, 81, 543-555.

15 T. D. Hinds, B. Peck, E. Shek, S. Stroup, J. Hinson, S. Arthur and J. S. Marino, Int. J. Mol. Sci., 2016, 17, 232.

16 P. Wang, L. P. Xu, X. H. Jin, J. Yang, R. H. Liu and X. J. Wang, Zhongxiyi Jiehe Xuebao, 2010, 8, 80-85.

17 R. H. Liu, X. J. Wang, W. H. Zhang, Y. Yuan and P. Wang, China J. Tradit. Chin. Med. Pharm., 2013, 28, 3215-3219.

18 X. Tang, X. Li, H. Nian, Y. Yang, Y. Chen, X. Wang, L. Xu, $\mathrm{X}$. Yang and R. Liu, Evidence-Based Complementary Altern. Med., 2017, 2017, 7961231.

19 K. Wei, Y. Xu, Z. Zhao, X. Wu, Y. Du, J. Sun, T. Yi, J. Dong and B. Liu, Int. J. Mol. Med., 2016, 38, 337-344.

20 B. Liu, H. Zhang, C. Xu, G. Yang, J. Tao, J. Huang, J. Wu, X. Duan, Y. Cao and J. Dong, Brain Res., 2011, 1375, 59-67.

21 S. S. Bachhav, S. D. Patil, M. S. Bhutada and S. J. Surana, Phytother. Res., 2011, 25, 1435-1439.

22 T. B. Ayeleso, M. G. Matumba and E. Mukwevho, Molecules, 2017, 22, 232.

23 Y. Liu, J. Ge, Q. Li, X. Guo, L. Gu, Z. G. Ma, X. H. Li and Y. P. Zhu, Leuk. Lymphoma, 2014, 55, 2179-2188.

24 A. R. Shibata, E. J. Troster and H. R. Wong, Pediatric critical care medicine, 2015, 16, e132-e140.

25 M. Bergquist, F. Huss, J. Hästbacka, C. Lindholm, C. Martijn, C. Rylander, G. Hedenstierna and F. Fredén, Acta Anaesthesiol. Scand., 2016, 60, 213-221.

26 J. Du, M. Li, D. Zhang, X. Zhu, W. Zhang, W. Gu, Y. Feng, X. Zhai and C. Ling, Arthritis Res. Ther., 2009, 11, R108.

27 X. Yang, W. Yao, H. Liu, Y. Gao, R. Liu and L. Xu, Sci. Rep., 2017, 7, 1014.

28 A. L. Gruver-Yates, M. A. Quinn and J. A. Cidlowski, Endocrinology, 2014, 155, 463-474.

29 M. J. Olnes, Y. Kotliarov, A. Biancotto, F. Cheung, J. Chen, R. Shi, H. Zhou, E. Wang, J. S. Tsang, R. Nussenblatt and CHI Consortium, Sci. Rep., 2016, 6, 23002.

30 P. J. Chang, C. Michaeloudes, J. Zhu, N. Shaikh, J. Baker, K. F. Chung and P. K. Bhavsar, Am. J. Respir. Crit. Care Med., 2015, 191, 54-62. 
31 A. L. Miller, M. S. Webb, A. J. Copik, Y. Wang, B. H. Johnson, R. Kumar and E. B. Thompson, Mol. Endocrinol., 2005, 19, 1569-1583.

32 K. Oneda, Arerugi, 1999, 48, 13-22.

33 C. A. Butler, S. McQuaid, C. C. Taggart, S. Weldon, R. Carter, G. Skibinski, T. J. Warke, D. F. Choy, L. P. McGarvey, P. Bradding, J. R. Arron and L. G. Heaney, Thorax, 2012, 67, 392-398.

34 X. Qian, Y. Zhu and W. Xu, Zhongxiyi Jiehe Xuebao, 2001, 81, 1496-1499.

35 Y. Matsumura, Int. J. Biomed. Sci., 2010, 6, 158-166.

36 Y. Chen, J. H. Huang, Y. Ning and Z. Y. Shen, Zhongxiyi Jiehe Xuebao, 2011, 9, 1179-1184.

37 L. Žiberna, D. Šamec, A. Mocan, S. F. Nabavi, A. Bishayee, A. A. Farooqi, A. Sureda and S. M. Nabavi, Int. J. Mol. Sci., 2017, 18, pii: E643.

38 C. Lin, X. Wen and H. Sun, Expert Opin. Ther. Pat., 2016, 26, 643-655.

39 R. M. Evans, Mol. Endocrinol., 2005, 19, 1429-1438.

40 A. L. Gruver-Yates, M. A. Quinn and J. A. Cidlowski, Endocrinology, 2014, 155, 463-474.

41 M. J. Herold, K. G. McPherson and H. M. Reichardt, Cell. Mol. Life Sci., 2006, 63, 60-72.
42 P. Demoly, M. Mathieu, J. Bousquet, F. B. Michel and P. Godard, Presse Med., 1996, 25, 769-774.

43 M. T. Bailey, S. G. Kinsey, D. A. Padgett, J. F. Sheridan and B. Leblebicioglu, Physiol. Behav., 2009, 98, 351-358.

44 N. Z. Lu and J. A. Cidlowski, Ann. N. Y. Acad. Sci., 2004, 1024, 102-123.

45 M. R. Yudt, C. M. Jewell, R. J. Bienstock and J. A. Cidlowski, Mol. Cell. Biol., 2003, 23, 4319-4330.

46 L. Pujols, J. Mullol and C. Picado, Front. Biosci., Landmark Ed., 2010, 15, 789-800.

47 T. Kino, Y. A. Su and G. P. Chrousos, Cell. Mol. Life Sci., 2009, 66, 3435-3448.

48 B. Jakieła, G. Bochenek and M. Sanak, Pol. Arch. Med. Wewn., 2010, 120, 214-222.

49 I. J. Brogan, I. A. Murray, G. Cerillo, M. Needham, A. White and J. R. Davis, Mol. Cell. Endocrinol., 1999, 157, 95-104.

50 N. O. Vamvakopoulos, Mol. Cell. Endocrinol., 1993, 98, 49-54.

51 D. Picard, B. Khursheed, M. J. Garabedian, M. G. Fortin, S. Lindquist and K. R. Yamamoto, Nature, 1990, 348, 166168.

52 M. Matysiak, B. Makosa, A. Walczak and K. Selmaj, Mult. Scler., 2008, 14, 919-926. 